\title{
18. MAGNETIC PROPERTIES OF BASALTS FROM DEEP SEA DRILLING PROJECT LEG 83: THE ORIGIN OF REMANENCE AND ITS RELATION TO TECTONIC AND CHEMICAL EVOLUTION ${ }^{1}$
}

\author{
Guy M. Smith and Subir K. Banerjee, University of Minnesota ${ }^{2}$
}

\begin{abstract}
We have studied the magnetic properties of 22 samples from DSDP Leg 83 to determine the origin of remanence and its relationship to such problems as the tectonic and chemical evolution of the section, the depth of the magnetized layer, and the applicability of magnetic properties of ophiolites to the marine crust. The magnitude of natural remanence has fairly typical values in the uppermost part of the section, falls two to three orders of magnitude in the transition zone, and returns to values slightly less than the upper part in the dike complex. This behavior reflects, for the most part, variations in the amount of magnetic minerals present. Directional behavior is highly variable throughout the section and often shows complexity even on the level of a single sample. Curie temperature measurements and preliminary opaque petrography indicate that the remanence is chemical in origin and probably involves a resetting of the original thermal remanent magnetization (TRM) direction. Selective destructive demagnetization of four breccia samples shows that the remanence of the clasts was acquired prior to consolidation and did not change significantly thereafter. There are also indications that some of the remanence may be carried by secondary magnetic phases. A comparison of these samples with comparable ophiolite rocks is equivocal, with similarities in remanence characteristics but differences in magnetic mineralogy. As for magnetic anomalies, the transition zone is too weakly magnetized to contribute significantly. The available data on the dike complex are inconclusive and their contribution is still open to debate.
\end{abstract}

\section{INTRODUCTION}

This study reports the magnetic properties of 22 samples of igneous rocks recovered during the Leg 83 coring in Hole 504B. The principal objective of this work is to investigate the origin of remanence in these samples and the relationship of remanent and intrinsic magnetic properties to the alteration regime in this section of oceanic crust. This information is relevant to a variety of topics including the depth of the magnetic layer contributing to magnetic anomalies (e.g., Johnson, 1979) and the applicability of ophiolite magnetic data to actual marine crust (e.g., Butler et al., 1976; Levi et al., 1978; BeskeDiehl and Banerjee, 1979; Banerjee, 1980; Luyendyk et al., 1982; Swift and Johnson, in press). Some of this information should be relevant also to the more general question of the nature of the hydrothermal alteration that took place in much if not all of the section sampled by Leg 83 .

We measured a number of standard magnetic properties including (1) intensity, direction, and stability of natural remanent magnetization (NRM); (2) intensity and stability of anhysteretic remanent magnetization (ARM); (3) hysteresis loop parameters: saturation magnetization, $J_{s}$, saturation remanence, $J_{r}$, coercivity, $H_{c}$, remanent coercivity, $H_{c r}$, and paramagnetic susceptibility, $\chi_{p}$; (4) weak field susceptibility, $\chi_{0} ;(5)$ thermomagnetic measurements: Curie temperature, $T_{c}$, and thermomagnetic curve characteristics.

\footnotetext{
${ }^{1}$ Anderson, R. N., Honnorez, J., Becker, K., et al., Init. Repts. DSDP, 83: Washington (U.S. Govt. Printing Office).

2 Address: Department of Geology and Geophysics, University of Minnesota, Minneapolis, MN 55455.
}

We also performed two less conventional procedures (at least for marine rocks): (6) selective destruction demagnetization, SDD (Larson, 1981), of breccia samples; (7) thermal demagnetization (TDM) and laboratory-induced TRM for selected samples.

\section{EXPERIMENTAL METHODS}

Magnetic remanence measurements were made on a Schonstedt spinner magnetometer or (for weak samples) an SCT cryogenic magnetometer coupled to Hewlett-Packard computer. AF demagnetization and ARM induction were done in a Schonstedt single-axis demagnetizer. ARMs were produced with a peak alternating field of $1000 \mathrm{Oe}$ and a coaxial bias field of $0.5 \mathrm{Oe}$. Sample holder remanence was negligible for the Schonstedt instrument. The measuring procedure for the SCT averaged out sample holder effects.

Hysteresis loops were obtained using a Princeton Applied Research vibrating sample magnetometer coupled to an $x-y$ recorder. Thermomagnetic measurements were also obtained on this instrument with an automatically controlled heating rate and in a vacuum of better than $10^{-6}$ torr. Temperature calibration is based on measurements of pure $\mathrm{Ni}$ and pure $\mathrm{Fe}_{3} \mathrm{O}_{4}\left(T_{c} \mathrm{~s}\right.$ are 358 and $580^{\circ} \mathrm{C}$, respectively). Curie temperatures were obtained by the graphical method (e.g., Moskowitz, 1981). Weak-field susceptibility was measured with a Conservation Instruments ("Bartington") bridge.

TRM induction and thermal demagnetization were done inside a six-layer mu-metal shield that reduces the external field to less than 50 gammas. Heating was performed in a vacuum better than $10^{-4}$ torr. The bias field for TRM induction was 0.5 Oe. SDD was performed with a Foredom cable tool with diamond tips (see later for detail).

\section{RESULTS}

The results of Measurements 1 through 5 (see Introduction) are given in Tables 1 and 2. Measurements 6 and 7 will be discussed separately.

\section{Natural Remanent Magnetization \\ NRM intensities $\left(J_{N}\right)$ showed a wide range from 2.37 $\times 10^{-3} \mathrm{emu} / \mathrm{cm}^{3}$ to $4.00 \times 10^{-6} \mathrm{emu} / \mathrm{cm}^{3}\left(6.20 \times 10^{-6}\right.$}


Table 1. Remanent magnetic properties, Hole 504B.

\begin{tabular}{|c|c|c|c|c|c|c|c|c|c|c|c|c|}
\hline \multirow{2}{*}{$\begin{array}{c}\text { Sample } \\
\text { (interval in cm) }\end{array}$} & \multirow{2}{*}{$\begin{array}{c}\text { Depth } \\
\text { (m) }\end{array}$} & \multirow[b]{2}{*}{$J_{N}$} & \multirow[b]{2}{*}{$I_{O}$} & \multirow[b]{2}{*}{$I_{C}$} & \multirow[b]{2}{*}{$\mathrm{MDF}_{\mathrm{N}}$} & \multirow[b]{2}{*}{$J_{A}$} & \multirow[b]{2}{*}{$\mathrm{MDF}_{\mathrm{A}}$} & \multirow{2}{*}{$\frac{J_{A}}{J_{N}}$} & \multicolumn{4}{|l|}{$\mathrm{MDF}_{\mathrm{A}}$} \\
\hline & & & & & & & & & $\overline{\mathrm{MDF}_{\mathrm{N}}}$ & $x_{0}$ & $Q$ & Description \\
\hline $71-1,17-19$ & 836 & $3.32 \times 10^{-3}$ & -39 & -34 & 163 & $2.57 \times 10^{-3}$ & 281 & 0.77 & 1.72 & $1.64 \times 10^{-3}$ & 6.0 & Pillow interior \\
\hline $73-157-59$ & 853 & $2.70 \times 10^{-3}$ & -10 & -47 & 247 & $2.51 \times 10^{-3}$ & 285 & 0.93 & 1.15 & $1.44 \times 10^{-3}$ & 5.5 & Massive basalt \\
\hline $78-2,21-23$ & 898 & $1.14 \times 10^{-3}$ & -14 & -38 & 153 & $1.52 \times 10^{-3}$ & 168 & 1.33 & 1.10 & $1.45 \times 10^{-3}$ & 2.3 & Pillow interior \\
\hline $78-2,47-49$ & 898 & $1.20 \times 10^{-3}$ & -23 & -26 & 189 & $2.11 \times 10^{-3}$ & 230 & 1.76 & 1.22 & $1.02 \times 10^{-3}$ & 3.5 & Massive basalt \\
\hline $79-1,22-24$ & 905 & $2.26 \times 10^{-5}$ & +1 & -5 & 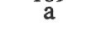 & & & & & $9.14 \times 10^{-5}$ & 0.7 & Breccia \\
\hline $79-2,14-16$ & 910 & $4.56 \times 10^{-4}$ & -12 & -14 & 394 & $5.19 \times 10^{-4}$ & 564 & 1.14 & 1.43 & $9.86 \times 10^{-5}$ & 13.6 & Massive basalt \\
\hline $80-3,9-11$ & 925 & $2.37 \times 10^{-6}$ & -17 & (b) & 507 & $1.28 \times 10^{-4}$ & 585 & 54.0 & 1.15 & $3.14 \times 10^{-5}$ & 0.2 & Breccia \\
\hline $82-2,64-66$ & 932 & $1.03 \times 10^{-3}$ & -56 & -60 & 207 & $1.70 \times 10^{-3}$ & 309 & 1.65 & 1.49 & $4.89 \times 10^{-4}$ & 6.2 & Pillow interior \\
\hline $85-1,87-89$ & 956 & $4.00 \times 10^{-6}$ & +11 & b & 245 & $2.57 \times 10^{-5}$ & 429 & 6.43 & 1.75 & $2.40 \times 10^{-5}$ & 0.5 & Breccia \\
\hline $85-2,61-63$ & 960 & $7.20 \times 10^{-4}$ & +2 & +3 & 367 & $1.35 \times 10^{-3}$ & 383 & 1.88 & 1.04 & $1.10 \times 10^{-4}$ & 19.2 & Massive basalt \\
\hline $91-1,21-23$ & 1004 & $2.50 \times 10^{-4}$ & +38 & +24 & 548 & $3.89 \times 10^{-4}$ & 656 & 1.56 & 1.20 & $3.98 \times 10^{-5}$ & 18.5 & Breccia \\
\hline $91-4,26-28$ & 1010 & $6.20 \times 10^{-6}$ & +28 & -16 & 544 & $1.25 \times 10^{-4}$ & 575 & 20.2 & 1.06 & $3.66 \times 10^{-5}$ & 0.5 & Massive basalt \\
\hline $92-1,51-53$ & 1012 & $1.50 \times 10^{-5}$ & +42 & (b) & 266 & $1.23 \times 10^{-4}$ & 515 & 8.20 & 1.94 & $4.09 \times 10^{-5}$ & 1.1 & Massive basalt \\
\hline $92-3,50-52$ & 1020 & $2.30 \times 10^{-5}$ & -15 & -14 & 484 & $8.58 \times 10^{-5}$ & 603 & 3.73 & 1.25 & $4.12 \times 10^{-5}$ & 1.6 & Pillow interior \\
\hline $92-3,97-99$ & 1020 & $4.36 \times 10^{-5}$ & -13 & -14 & 578 & $1.31 \times 10^{-4}$ & 592 & 2.98 & 1.02 & $4.20 \times 10^{-5}$ & 3.1 & Pillow margin ${ }^{c}$ \\
\hline $94-3,40-42$ & 1036 & $2.09 \times 10^{-5}$ & +19 & +5 & 372 & $3.02 \times 10^{-4}$ & 617 & 14.4 & 1.66 & $5.14 \times 10^{-5}$ & 1.2 & Pillow interior \\
\hline $100-1,113-115$ & 1081 & $5.60 \times 10^{-4}$ & -12 & -13 & 599 & $6.25 \times 10^{-4}$ & 617 & 1.12 & 1.03 & $6.28 \times 10^{-5}$ & 26.2 & Fractured basalt \\
\hline $107-1,30-32$ & 1150 & $1.99 \times 10^{-3}$ & -52 & (b) & 16 & $4.28 \times 10^{-3}$ & 114 & 2.15 & 7.13 & $6.49 \times 10^{-3}$ & 0.9 & Breccia \\
\hline $107-1,136-138$ & 1150 & $1.16 \times 10^{-3}$ & +14 & +13 & 300 & $2.46 \times 10^{-3}$ & 349 & 2.12 & 1.16 & $1.11 \times 10^{-3}$ & 3.1 & Massive basalt \\
\hline $108-1,28-30$ & 1152 & $1.25 \times 10^{-3}$ & -19 & -16 & 319 & $2.52 \times 10^{-3}$ & 432 & 2.02 & 1.35 & $1.08 \times 10^{-3}$ & 3.4 & Massive basalt \\
\hline $121-1,71-73$ & 1208 & $9.85 \times 10^{-4}$ & -25 & -36 & 232 & $2.98 \times 10$ & 318 & 3.01 & 1.37 & $9.63 \times 10^{-4}$ & 3.0 & Massive basalt \\
\hline $122-1,45-47$ & 1214 & $1.75 \times 10^{-4}$ & +7 & +14 & 339 & $3.09 \times 10^{-4}$ & 364 & 1.77 & 1.07 & $1.06 \times 10^{-4}$ & 4.8 & Massive basalt \\
\hline
\end{tabular}

Note: $J_{N}$ is the intensity of NRM in emu $/ \mathrm{cm}^{3} ; I_{O}$ is the inclination prior to magnetic cleaning; $I_{C}$ is the stable inclination; $M D F_{N}$ is the median demagnetizing field of NRM in Oe; $J_{A}$ is the intensity of ARM in emu/ $\mathrm{cm}^{3} ; M D F_{A}$ is the median demagnetizating field of ARM in Oe; $\chi_{O}$ is the low-field susceptibility in emu/ $\left(\mathrm{Oe}^{-\mathrm{I}_{-}}-\mathrm{cm}^{3}\right) ; Q$ is the koenigsberger ratio $\left(J_{N} / 0.34 \chi_{0}\right)$.

${ }^{\mathrm{a}} M D F$ greater than $1000 \mathrm{Oe}$.

$\mathrm{b}$ No stable inclination was reached.

${ }^{c}$ Sample may be misoriented (personal communication, DSDP staff).

Table 2. Hysteresis properties and Curie temperatures, Hole 504B.

\begin{tabular}{|c|c|c|c|c|c|c|c|c|c|c|c|c|c|}
\hline \multirow{2}{*}{$\begin{array}{c}\text { Sample } \\
\text { (interval in cm) }\end{array}$} & \multirow{2}{*}{\multicolumn{2}{|c|}{$J_{S}$}} & \multirow{2}{*}{\multicolumn{2}{|c|}{$J_{r}$}} & \multirow[b]{2}{*}{$H_{c}$} & \multirow[b]{2}{*}{$H_{c r}$} & \multirow{2}{*}{$\begin{array}{l}J_{r} \\
J_{S}\end{array}$} & \multicolumn{2}{|l|}{$H_{c r}$} & \multicolumn{2}{|c|}{$T_{c}$} & \multicolumn{2}{|l|}{$J_{f}$} \\
\hline & & & & & & & & $\overline{H_{c}}$ & $\chi_{p}$ & Heating & Cooling & $J_{i}$ & Description \\
\hline $71-1,17-19$ & 0.767 & & 0.113 & & 113 & 234 & 0.15 & 2.1 & 1.4 & 495 & 465 & 0.87 & \\
\hline $73-1,57-59$ & 0.981 & & 0.236 & & 197 & 334 & 0.24 & 1.7 & 1.3 & 535 & 485 & 0.73 & \\
\hline $78-2,21-23$ & 0.607 & & 0.124 & & 155 & 259 & 0.20 & 1.7 & 1.3 & 560 & 580 & 0.91 & \\
\hline $78-2,47-49$ & 0.835 & & 0.209 & & 178 & 264 & 0.25 & 1.5 & 1.5 & 550 & 575 & 0.95 & \\
\hline $79-1,22-24$ & 2.62 & $\times 10^{-2}$ & 6.73 & $\times 10^{-3}$ & 170 & 414 & 0.26 & 2.4 & 1.2 & 570 & 585 & 1.03 & \\
\hline $79-2,14-16$ & 2.42 & $\times 10^{-2}$ & 1.74 & $\times 10^{-2}$ & 248 & 411 & 0.32 & 1.6 & 1.0 & 580 & 585 & 0.93 & \\
\hline \multirow[t]{3}{*}{$80-3,9-11$} & 9.6 & $\times 10^{-3}$ & & & & & & & 1.1 & & & & Breccia matrix \\
\hline & 2.4 & $\times 10^{-2}$ & 3.4 & $\times 10^{-3}$ & 108 & 513 & 0.14 & 6.3 & 0.75 & & & & Clast \\
\hline & 1.6 & $\times 10^{-2}$ & 3.9 & $\times 10^{-3}$ & 125 & 438 & 0.25 & 3.5 & 1.1 & 565 & 575 & 0.90 & Clast \\
\hline \multirow{3}{*}{$85-1,87-89$} & 0.489 & & 0.105 & & 172 & 208 & 0.22 & 1.2 & 1.3 & 570 & 590 & 0.90 & \\
\hline & 5.09 & $\times 10^{-2}$ & 5.7 & $\times 10^{-3}$ & 119 & 230 & 0.11 & 1.9 & 1.2 & 555 & 580 & 0.83 & Clast \\
\hline & $\begin{array}{l}3.24 \\
1.7\end{array}$ & $\begin{array}{l}\times 10^{-2} \\
\times 10^{-2}\end{array}$ & & & & & & & 1.3 & & & & Quart \\
\hline \multirow{3}{*}{$91-1,51-53$} & 1.5 & $\begin{array}{l}\times 10^{-2} \\
\times 10^{-2}\end{array}$ & & & & & & & 1.1 & $\begin{array}{l}570 \\
570\end{array}$ & 580 & 1.0 & \\
\hline & $\begin{array}{l}1.5 \\
1.8\end{array}$ & $\begin{array}{l}\times 10^{-2} \\
\times 10^{-2}\end{array}$ & 5.6 & $\times 10^{-3}$ & 197 & 591 & 0.32 & 3.0 & $\begin{array}{l}1.6 \\
1.4\end{array}$ & 570 & 390 & 1.1 & $\begin{array}{l}\text { Breccia matrix } \\
\text { Clast }\end{array}$ \\
\hline & 1.4 & $\times 10^{-2}$ & 4.5 & $\times 10^{-3}$ & 201 & 899 & 0.33 & 4.5 & 2.7 & & & & Clast \\
\hline $91-4,26-28$ & 4.1 & $\times 10^{-3}$ & & & & & & & 1.2 & 595 & 575 & 1.0 & \\
\hline $92-1,51-53$ & 5.5 & $\times 10^{-3}$ & & & & & & & 0.96 & 595 & & 1.0 & \\
\hline $92-3,50-52$ & 5.7 & $\times 10^{-3}$ & & & & & & & 1.1 & 585 & 570 & 0.93 & \\
\hline $92-3,97-99$ & 9.4 & $\times 10^{-3}$ & 2.3 & $\times 10^{-3}$ & 84 & 375 & 0.24 & 4.5 & 1.6 & 580 & 565 & 0.97 & \\
\hline $94-3,40-42$ & 1.8 & $\times 10^{-2}$ & 5.8 & $\times 10^{-3}$ & 163 & 434 & 0.33 & 2.7 & 1.3 & 585 & 560 & 0.70 & \\
\hline $100-1,113-115$ & 2.64 & $\times 10^{-2}$ & 1.0 & $\times 10^{-2}$ & 231 & 631 & 0.38 & 2.7 & 1.7 & 580 & 570 & 0.93 & \\
\hline \multirow[t]{2}{*}{$107-1,30-32$} & 2.92 & & 0.261 & & 81 & 222 & 0.08 & 2.7 & 2.0 & & & & Clast \\
\hline & 2.47 & & 0.284 & & 108 & 209 & 0.12 & 1.9 & 1.3 & 550 & 570 & 0.97 & Clast \\
\hline $107-1,136-138$ & 1.19 & & 0.340 & & 247 & 413 & 0.29 & 1.7 & 1.6 & 560 & 580 & 0.97 & \\
\hline $108-1,28-30$ & 0.901 & & 0.306 & & 298 & 461 & 0.34 & 1.5 & 1.5 & 565 & 570 & 0.90 & \\
\hline $121-1,71-73$ & 1.18 & & 0.330 & & 231 & 366 & 0.28 & 1.6 & 1.8 & 570 & 590 & 0.93 & \\
\hline $122-1,45-47$ & 9.11 & $\times 10^{-2}$ & 1.7 & $\times 10^{-2}$ & 134 & 283 & 0.18 & 2.1 & 1.7 & 570 & 580 & 1.0 & \\
\hline
\end{tabular}

Note: $J_{S}$ is the saturation magnetization is emu/g; $J_{r}$ is the saturation remanence in emu/g; $H_{C}$ is the coercivity in Oe; $H_{C r}$ is the coercivity of remanence in Oe; $\chi_{p}$ is the paramagnetic susceptibility in $10^{-5} \mathrm{emu} /\left(\mathrm{g}\right.$-Oe); $T_{c}$ is the Curie temperature in ${ }^{\circ} \mathrm{C} ; J_{f} / J_{i}$ is the ratio of magnetization following the $T_{C}$ determination. 
excluding breccias). They are plotted against sub-bottom depth in Figure 1A along with the generalized structure of the section. A rough average value for 5.9-m.y. old pillow basalts $\left(2 \times 10^{-3} \mathrm{emu} / \mathrm{cm}^{3}\right.$, Bleil and Peterson, 1983 ) is plotted for reference (dashed line). This value is somewhat less than the value observed by Furuta and Levi (1983) for the upper $550 \mathrm{~m}\left(5-10 \times 10^{-3}\right)$. The general pattern is that of typical magnetizations in the upper units decreasing to very low values toward the base of the transition zone and increasing again with depth to values close to the upper units. It is uncertain from the available data what the trend is at even greater depth. Initial inclinations (i.e., prior to magnetic cleaning) are shown in Figure 1B. The expected value should be close to zero as the site has not changed latitude significantly since it was formed (Chase, 1978). There is considerable scatter including both positive and negative inclinations. Those units above the stockwork are all negative and those below show mixed polarities with no apparent pattern. This behavior is only slightly altered by cleaning (Fig. 1C). While the inclinations are generally more negative, there is still a large scatter including both positive and large negative values. Some closely spaced pairs showed virtually identical behavior, but others (particularly the two deepest pairs) showed significantly different values.

All samples were stepwise demagnetized to either $<10 \%$ of their original remanence remaining or 1000 Oe (the maximum value available on our demagnetizer). The stability of remanence appeared to be fairly good. Median demagnetizing fields $\left(\mathrm{MDF}_{\mathrm{N}}\right)$ were largely in excess of $200 \mathrm{Oe}$ and many exceeded $400 \mathrm{Oe}$ (with the notable exception of Sample 504B-107-1, 30-32 cm). Although there is considerable scatter, the general trend is

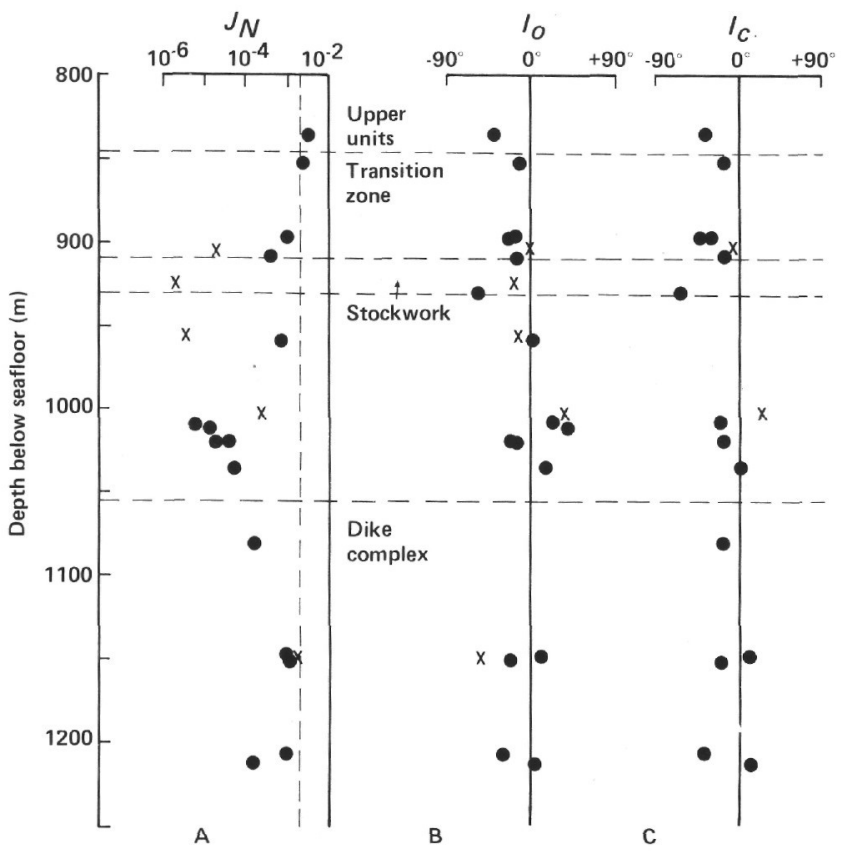

Figure 1. (A) Variation of the NRM intensity (in emu $/ \mathrm{cm}^{3}$ ) with depth. (B) Variation of the initial inclination with depth. (C) Variation of the cleaned inclination with depth. Crosses indicate breccia samples. for lower MDFs in the upper part, increasing in the transition zone and decreasing again in the dike complex.

In order to make some sense out of the complexities of the magnetization behavior, Zijderveldt plots were constructed for all samples (an arbitrary declination is given with respect to sample coordinates). These are helpful in determining whether a stable inclination has been reached, and they also allow some inferences to be made about the magnetization history of the sample.

One possibility that is particularly important to check for is the presence of a "drill string" remanence (i.e., a remanence acquired as a result of the drilling itself). It typically has a vertical inclination and may overprint part or even all of the NRM. It appears on a Zijderveldt plot as a vertical line in the $z, h$ plane starting at the NRM value. Only three samples showed removal of an initial steep inclination and these were all significantly less than $90^{\circ}$, the closest being about $80^{\circ}$ (Sample 504B91-1, 21-23 cm). It seems reasonable to conclude that drilling has had a minimal effect on the NRM of these samples.

Fourteen samples showed removal of an initial lowangle component at low demagnetizing fields $(<100 \mathrm{Oe})$. A typical example is shown in Figure 2A. Most had either positive or zero inclination, although three did show negative values. These are sufficiently small that they might have been the result of a slight misorientation of the sample. Since the current field is positive at the site, these components probably represent relatively recent (since the last geomagnetic reversal) viscous remanence. There is, however, some possibility that these are not recent acquisitions. The estimated geocentric axial dipole value for inclination at the site is $+2^{\circ}$, and the observed value as of 1966 is about $+25^{\circ}$ (Garland, 1982), which brackets many of the initial components. This suggests that they may be neither very recent nor relatively longterm averages ( $>10-20,000$ yr.) and may instead be stable remanences. In any case, these components comprise less than $10 \%$ of the sample remanences, which suggests that VRM is not a large factor in the total remanence.

Many of the samples had secondary components that persisted to relatively large demagnetization levels and are probably not due to viscous processes. Unfortunately, there is no unequivocal means of determining how much of the remanence is viscous. A somewhat arbitrary dividing line of $100 \mathrm{Oe}$ was used to distinguish "nonviscous" from "viscous" components. This value may be too low (or too high), and interpretations based on this division should be regarded with due caution.

Four Hole 504B samples (79-2, 14-16 cm; 91-1, 21$23 \mathrm{~cm}$; 91-4, 26-28 cm; 100-1, 113-115 cm) show relatively simple multicomponent behavior, that is, straight lines with fairly sharp angles on the Zijderveldt plots (Figs. 2B-D, 3A). These are generally interpreted as resulting from at least two distinct episodes of magnetization. One possibility could be moderate reheating at some time after the primary remanence is acquired that resets the low blocking temperature grains to a different direction. The samples consist of a massive basalt from the 

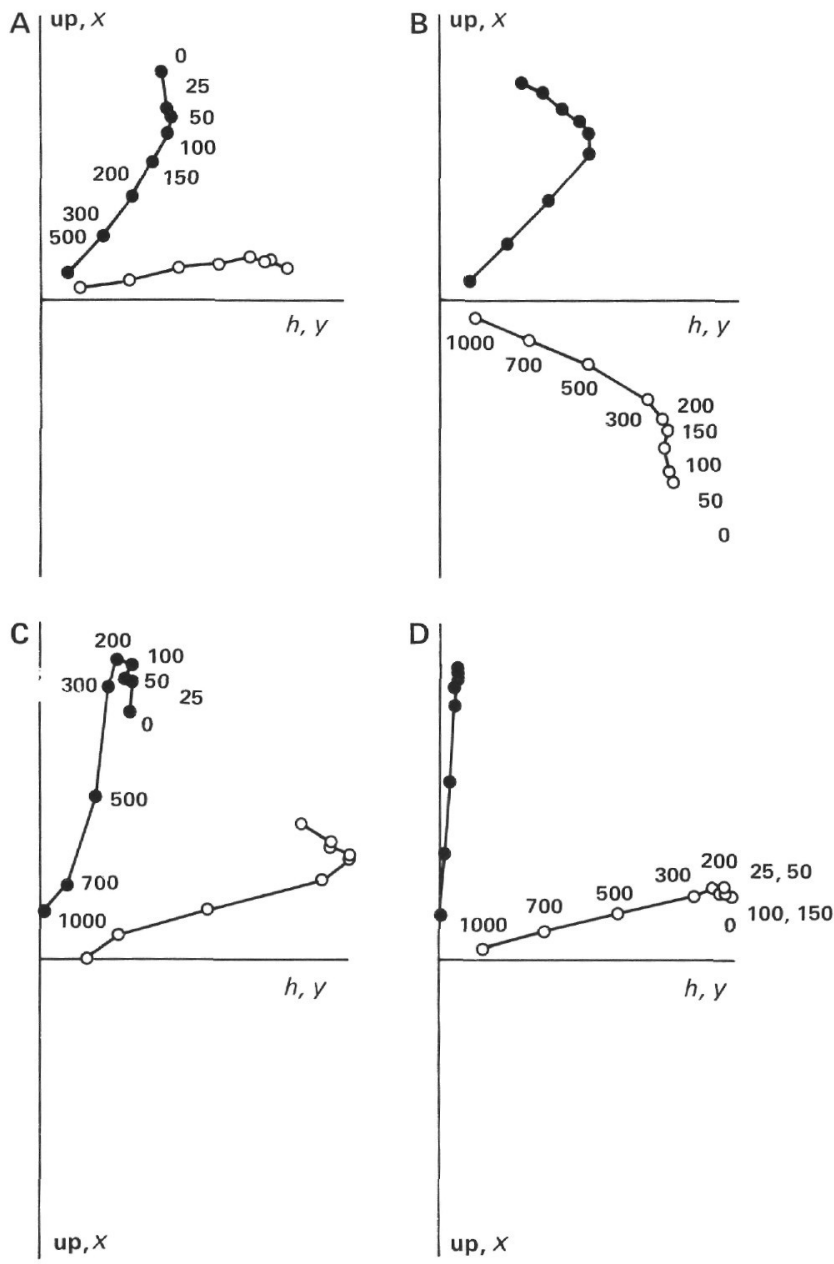

Figure 2. Zijderveldt (vector) plots of the demagnetization behavior of (A) Sample 504B-122-1, 45-47 cm; (B) Sample 504B-91-1, 21-23 $\mathrm{cm}$; (C) Sample 504B-91-4, 26-28 cm; and (D) Sample 504B-100-1, $115-115 \mathrm{~cm}$. Closed circles represent the $x-y$ component and open circles the vertical plane.

upper part of the transition zone and a breccia and two massive basalts from the lower part. The two samples from Core 504B-91 are close to each other and yet show little similarity in their plots. Samples 504B-79-2, 14-16 $\mathrm{cm}$ and 504B-100-1, 113-115 cm appear similar to Sample 504B-122-1, 45-47 cm in that they have a short positive initial component. These two samples were categorized as multicomponent because the initial component persisted to $200 \mathrm{Oe}$, but it is possible that the soft remanence may be viscous.

Another eight samples show behavior that cannot be interpreted in such a simple fashion. Several Hole 504B samples show only one apparent component, but fail to converge on the origin $(82-2,64-66 \mathrm{~cm} ; 92-1,51-53 \mathrm{~cm}$; 92-3, 50-52 cm; 92-3, 97-99 cm; 94-3, 40-42 cm). The three Core 504B-92 samples are interesting in that they are relatively close together (Fig. 3B-D). The two from Section 3 show virtually identical behavior (note that the similarity in declination is fortuitous) and bear virtually no resemblance to Sample 504B-92-1, 51-53 cm. The other three samples (504B-78-2, 21-23 cm; 504B-85-2, 61-63 cm; 504B-121-1, 71-73 cm) showed curved paths
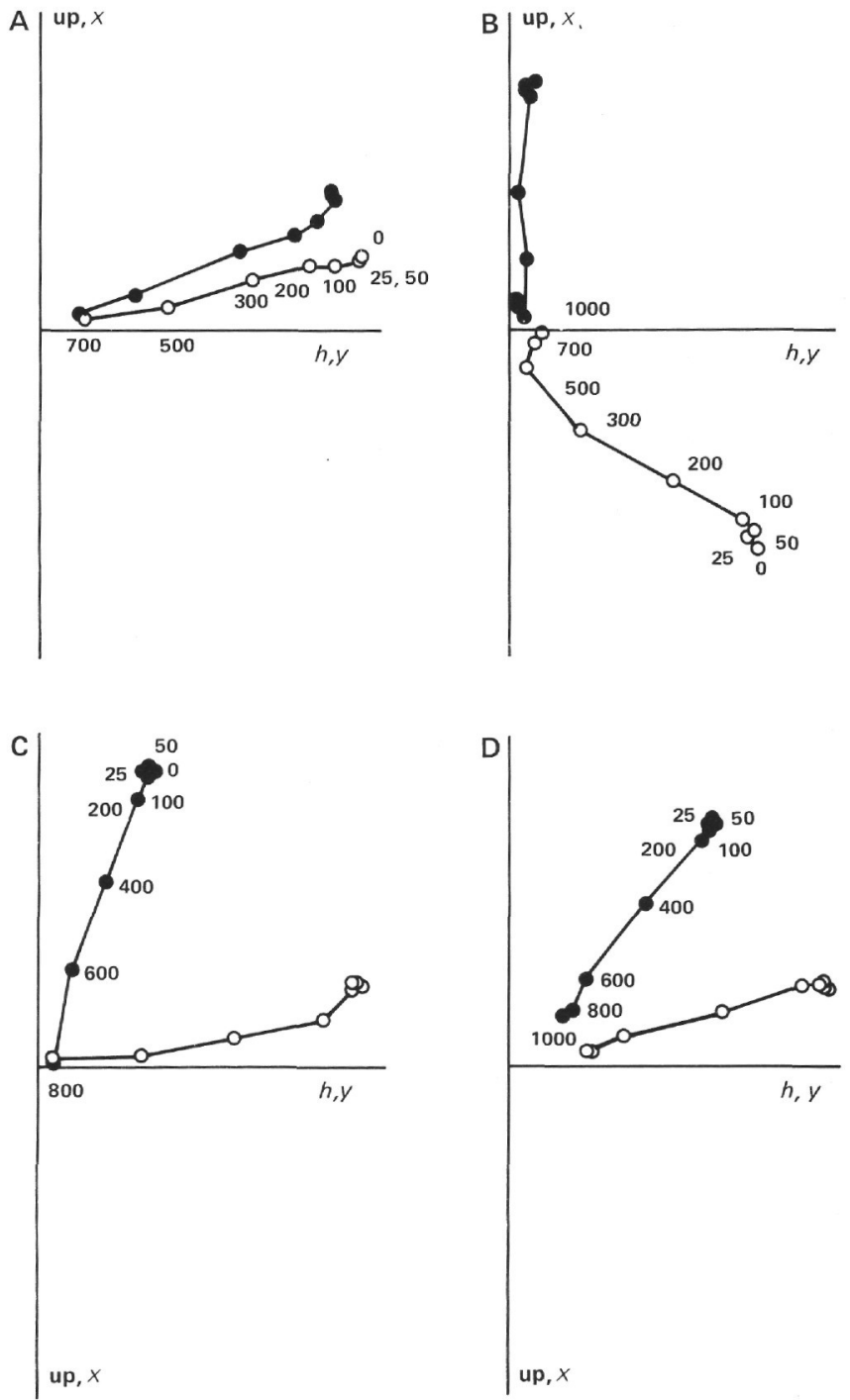

Figure 3. Zijderveldt plots of (A) Sample 504B-79-2, 14-16 cm; (B) Sample 504B-91-1, 51-53 cm; (C) Sample 504B-92-3, 50-52 cm; and (D) Sample 504B-92-3, 97-99 cm.

prior to achieving a stable direction. This is probably due to two or more components with overlapping coercivity spectra.

Six Hole 504B samples had relatively simple single component behavior, excluding a small, presumably viscous, low coercivity component $(71-1,17-19 \mathrm{~cm} ; 73-1$, $57-59 \mathrm{~cm} ; 78-2,21-23 \mathrm{~cm} ; 107-1,136-138 \mathrm{~cm} ; 108-1$, $28-30 \mathrm{~cm} ; 122-1,45-47 \mathrm{~cm})$. It is interesting that these samples only occurred in the upper and lower parts of the section and not in the transition zone. The four remaining samples were all breccias; three had erratic behavior and one (504B-79-1, 22-24 cm) did not demagnetize sufficiently to be interpreted unequivocally.

The Koenigsberger ratio, $Q$, is the ratio of remanent to induced magnetization (at low field). It was calculated by assuming a linear weak-field susceptibility and multiplying $\chi_{o}$ by $0.34 \mathrm{Oe}$, which is the approximate 1966 value at the site (Garland, 1982). This value is somewhat arbitrary, but seems as reasonable as any other. This ra- 
tio is generally greater than 1.0 with only a few exceptions, most of which are breccias, which are inhomogeneously magnetized. The others are all from the transition zone and have complex magnetization behavior.

\section{Anhysteretic Magnetization}

Anhysteretic remanence (ARM) is thought to provide a reasonably good model for TRM (e.g., Levi and Merrill, 1976). As such, ARMs were measured to provide some insight into the origin of magnetization in these rocks.

In general, ARM intensities $\left(J_{A}\right)$ behave much like $\operatorname{NRM}\left(J_{N}\right)$ : high in the upper units with a minimum in the transition zone and high again in the dikes (Fig. 4A). In detail, though, there are some significant differences. The ratio $J_{A} / J_{N}$ varied from 0.77 to 20.2 for nonbrecciated samples and from 1.56 to 54.0 for brecciated ones. (Note that the exact value of this ratio is dependent on the choice of ARM inducing field, which was arbitrarily set at $0.5 \mathrm{Oe}$.)

The fact that the ratio is large for most of the breccias is not surprising as the NRM is reduced substantially by inhomogeneous magnetization. There are, however, many intact samples that also have high values. The largest ratios are located in the transition zone, although the values from the dike complex still exceed the upper units.

The other parameter measured is the median demagnetizing field, $\mathrm{MDF}_{\mathrm{A}}$. Like intensity, it follows essentially the same pattern as $\mathrm{MDF}_{\mathrm{N}}$. In comparison, however, $\mathrm{MDF}_{\mathrm{A}}$ is consistently, and sometimes substantially, larg-

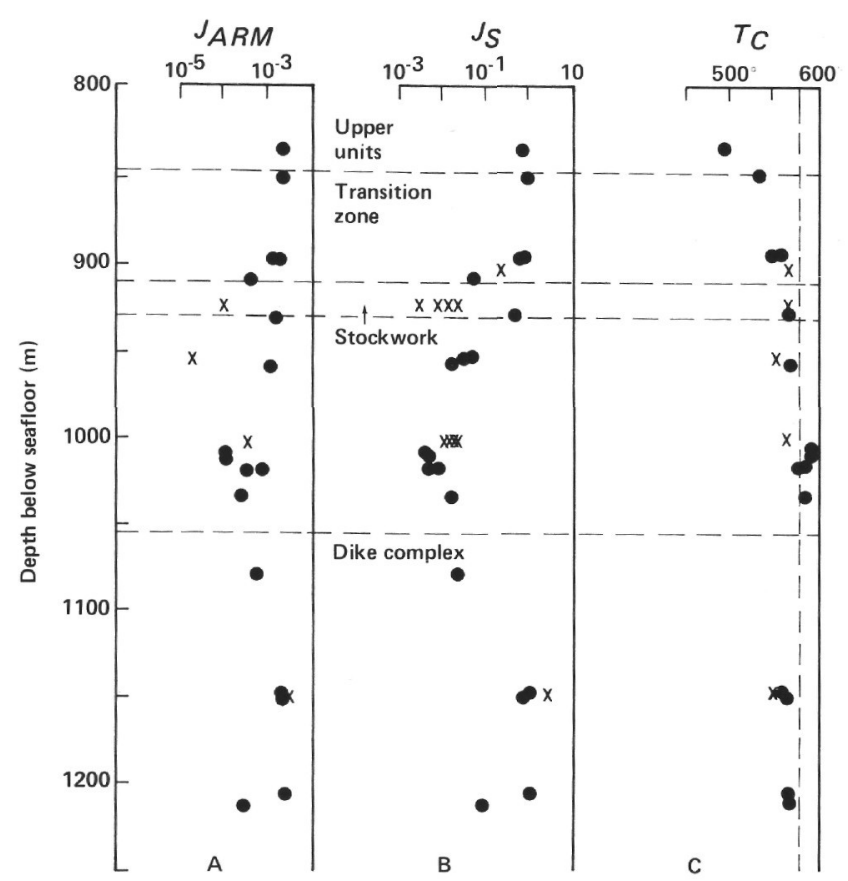

Figure 4. (A) Variation of ARM intensity (in emu/ $\mathrm{cm}^{3}$ ) with depth. (B) Variation of the saturation magnetization (in $\mathrm{emu} / \mathrm{g}$ ) with depth. (C) Variation of the Curie temperature (in ${ }^{\circ} \mathrm{C}$ ) with depth. Crosses indicate breccias. er than $\mathrm{MDF}_{\mathrm{N}}$, with the ratio varying from 1.03 to 7.13 . Unlike intensity of remanence, MDF is only weakly dependent on inducing field. This ratio is, in many cases, somewhat low as multicomponent magnetization, often seen with NRM, tends to produce an apparently "harder" AF demagnetization spectrum than a comparable single-component spectrum.

\section{Hysteresis Loop Parameters}

Hysteresis loop parameters are useful in characterizing the intrinsic magnetic behavior of rocks (see, e.g., Stacey and Banerjee, 1974) and are helpful in studying the problem of the origin of remanence.

Saturation magnetization, $J_{s}$, is a measure of the total amount of magnetic material in the sample (if the composition is known, it is an exact measurement). $J_{s}$ variation with depth is given in Figure 4B. It is similar to the NRM variation, with a minimum in the transition zone and high values at either end. Breccia values (with the exception of Sample 504B-107-1, 30-32 cm) are similar to intact samples. The values are greater in the dike complex than in the upper units, and the highest are somewhat larger than typical seafloor basalts. Since the compositional variation appears fairly limited (discussed in the following section), this parameter is a good reflection of the actual magnetic mineral content of the sample.

The coercivity, $H_{c}$, is a measure of magnetic stability, similar but not identical to the MDF. The values seen are variable and show no apparent trend. The lack of values in the transition zone, a result of insufficient magnetic material for accurate, measurement, make this statement somewhat tentative, however.

The two ratios, $J_{r} / J_{s}$ and $H_{c r} / H_{c}$, are commonly used as indicators of domain state and, indirectly, grain size (e.g., Day et al., 1977). High values of $J_{r} / J_{S}(>0.5)$ indicate small $(<0.1 \mu \mathrm{m}$ or so) single-domain (SD) grains, and low values $(<0.1)$ are characteristic of large $(>15-20 \mu \mathrm{m})$ multidomain grains (MD). The intermediate region is usually referred to as pseudosingle domain (PSD). $H_{c r} / H_{c}$ is a much less reliable parameter, but, conventionally, SD grains have a value of $\approx 1.2$, and MD grains should have values $>2-3$. The somewhat more reliable $J_{r s} / J_{S}$ ratio indicates that the grains should be predominanty PSD with effective grain sizes in the $0.1-15 \mu \mathrm{m}$ range. The simple model for magnetite on which this analysis is based may not be applicable here, however, and such classifications are probably valuable mostly for descriptive purposes.

The paramagnetic susceptibility, $\chi_{p}$, is the susceptibility of the sample in a magnetic field sufficient to saturate the ferromagnetic component. Hence, it is a function of all the minerals in the rock and is probably more reflective of the more numerous silicates. There appears to be a slight increase of $\chi_{p}$ with depth although the large scatter makes this trend questionable. It is interesting that both the lowest and highest values were from breccias, although some also had values similar to intact basalt. In general, $\chi_{p}$ seems to be a fairly unrevealing parameter. 


\section{Curie Temperature}

The temperature below which a magnetic mineral is magnetically ordered is called the Curie temperature, $T_{c}$. As this value is sensitive to composition, it is useful in understanding the magnetic mineralogy (e.g., it varies linearly with Ti content for titanomagnetites). It is determined by measuring the magnetization as a function of temperature and noting the point at which it approaches zero. A typical thermomagnetic curve from Leg 83 is shown in Figure 5A. This curve is not typical of that seen for marine basalts recovered from shallower depths, which normally contain titanomagnetites $(x=$ $0.6)$ with varying degrees of low-temperature oxidation. These titanomaghemites are metastable and invert to two-phase assemblage with compositions close to magnetite and ilmenite, yielding the characteristic thermomagnetic curve shown in Figure 5B. In the uncommon cases where the titanomagnetites are relatively unoxidized, a behavior similar to that shown in Figure 5A is observed, but $T_{c}$ is much lower $\left(150-200^{\circ} \mathrm{C}\right)$. The curves shown for all of the Leg 83 samples suggest that the dominant magnetic mineral is a relatively unoxidized low Ti titanomagnetite $(x<0.15)$. The variation of $T_{c}$ with depth is given in Figure 4C. Assuming that Ti is responsible for the variation, compositions range from 10
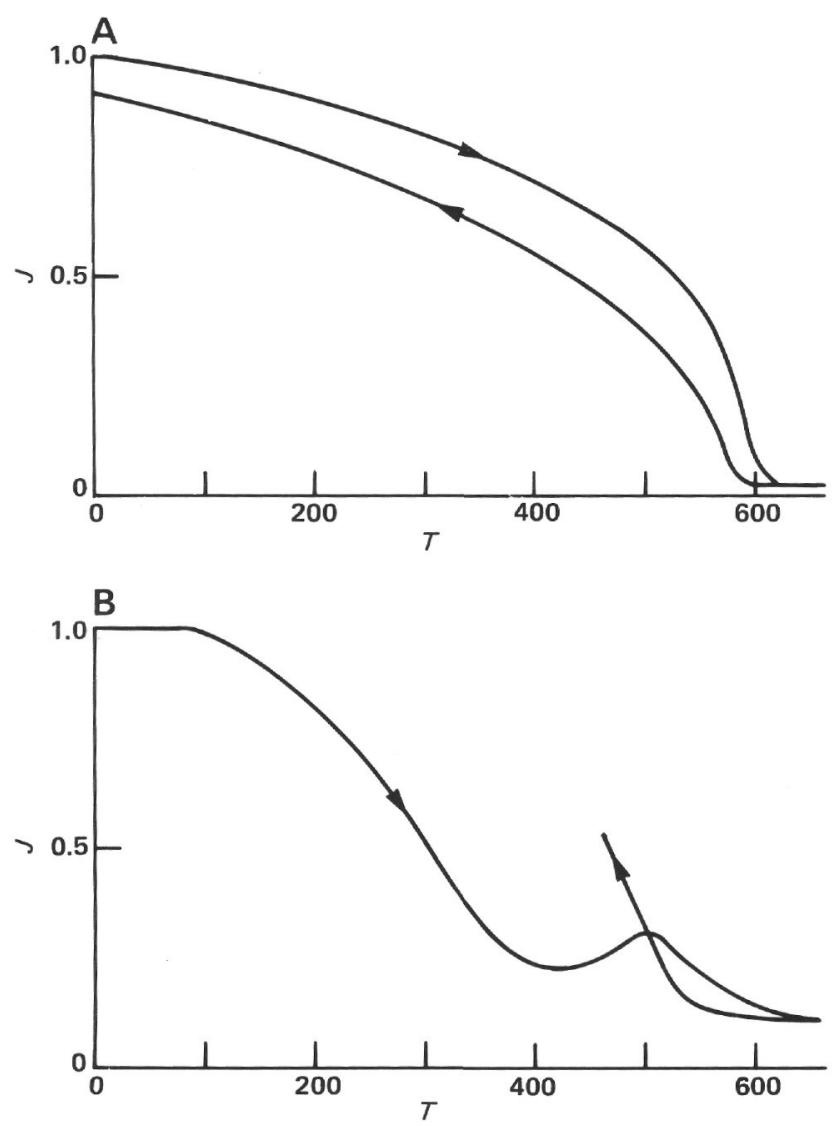

Figure 5. (A) Typical thermomagnetic curve for Leg 83 basalts. Vertical axis is in arbitrary units, horizontal is in ${ }^{\circ} \mathrm{C}$. (B) Thermomagnetic curve of a typical low-temperature oxidized basalt. Neither curve has been corrected for instrumental offset. to $15 \%$ ulvospinel $\left(T_{c}=495^{\circ} \mathrm{C}\right)$ to pure magnetite $\left(T_{c}\right.$ $=580^{\circ} \mathrm{C}$ ). There is a general trend for higher Ti content in the upper section going to zero in the transition zone and increasing slightly in the dike complex. The values of $T_{c}$ that are higher than $580^{\circ} \mathrm{C}$ are probably due to experimental error as the samples were weakly magnetic and difficult to measure. The ratio of final to initial magnetization indicates that some chemical alteration, generally slight, of the magnetic minerals took place during heating.

\section{Selective Destructive Demagnetization}

The breccia samples, with their low remanence and $Q$, are of negligible importance in producing magnetic anomalies. They can, however, offer some insight into the nature of the magnetization process occurring at these depths and also a view of the complex thermal, chemical, and mechanical processes of hydrothermal circulation. In the previous sections, the remanent behavior of the sample as a whole and the intrinsic magnetic properties of individual pieces were discussed. In this section we look at the remanent properties of portions of the samples, which, together with previous measurements, give a fairly good idea as to how these samples were magnetized.

The technique chosen, selective destructive demagnetization (SDD) (Larson, 1981), is straightforward, if tedious. It involves mounting a thin slice of the sample (1.5-2 $\mathrm{mm}$ in this case) on a slide and observing the change in remanence as portions are selectively removed. The removal was accomplished by simply grinding the pieces away with a diamond-tipped carving head mounted on a Foredom cable tool. Since there was a small field associated with the tool $(\approx 3 \mathrm{Oe})$, samples were demagnetized at 25 Oe prior to each measurement. The demagnetization generally caused minor changes, if any.

Of the five breccia samples, four were suitable for this technique (Sample 504B-79-1, 22-24 cm was too fine grained). Photographs of these samples are shown in Figure 6 along with numbers indicating the order in which pieces were removed. Sample 504B-80-3, 9-11 cm (Fig. 6A) consists of three large clasts $(1,2$, and 7$)$ in a lithic matrix. Some sulfides are present. Sample 504B$85-1,87-89 \mathrm{~cm}$ (Fig. 6B) has some small clasts (1, 2, and 3 ); some hydrothermal quartz (7 and 8); and the remainder is fine lithic fragments. There are numerous large sulfide grains $(<1 \mathrm{~mm})$ especially in the quartz regions. Sample 504B-91-1, 21-23 cm (Fig. 6C) consists of clasts of varying size cemented with a mixture of lithic fragments and a white mineral presumably of hydrothermal origin. It appears to have been heavily fractured rather than brecciated as the clasts seem to fit together quite well. There is little evidence of sulfides. Sample 504B$107-1,30-32 \mathrm{~cm}$ (Fig. 6D) is composed of clasts of varying size in a lithic matrix. Some sulfides are present as well as an abundant opaque phase that appears to be magnetite, rimming the clasts.

Inclination, declination (relative to sample coordinates), and intensity of remanence are given in Table 3. Note that errors may be relatively large for the smaller and/or earlier pieces, as the change in the total remanence caused 


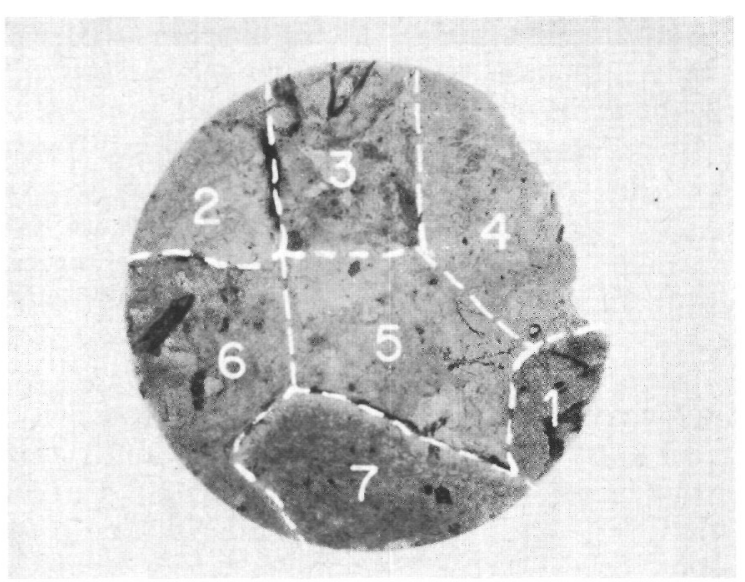

A

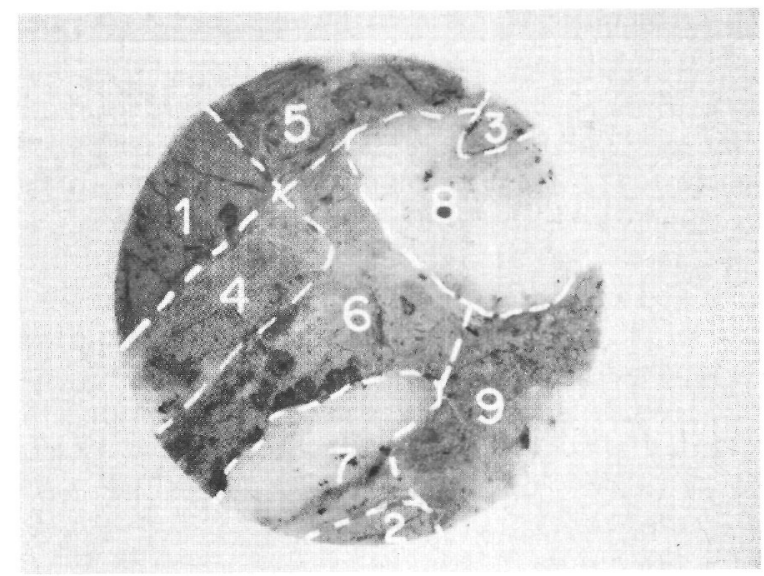

B

\section{$2 \mathrm{~cm}$}

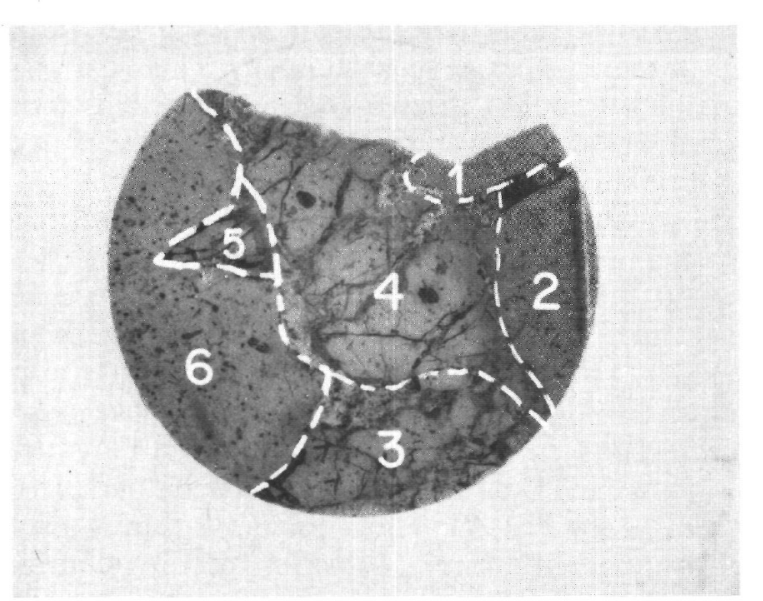

C

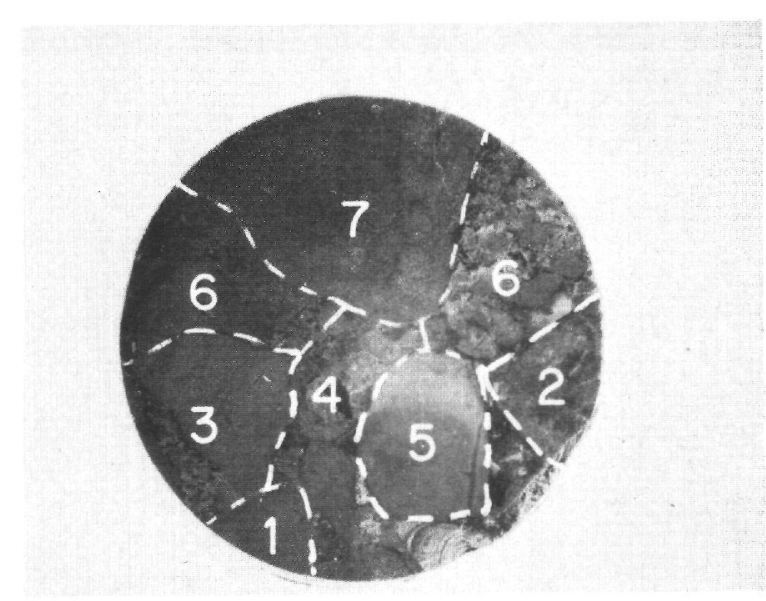

D

Figure 6. Photographs of the four breccia samples that underwent SDD. Numbers refer to the order of removal of their respective pieces. (A) Sample 504B-80-3, 9-11 cm; (B) Sample 504B-85-1, 87-89 cm; (C) Sample 504B-91-1, 21-23 cm; (D) Sample 504B-107-1, $30-32 \mathrm{~cm}$.

Table 3. Selective destructive demagnetization, Hole 504B.

\begin{tabular}{|c|c|c|c|c|c|c|c|}
\hline Piece & $I$ & $D$ & $J$ & Piece & $I$ & $D$ & $J$ \\
\hline \multicolumn{4}{|c|}{ Sample $80-3,9-11 \mathrm{~cm}$} & \multicolumn{4}{|c|}{ Sample $91-1,21-23 \mathrm{~cm}$} \\
\hline $\begin{array}{l}1 \\
2 \\
3 \\
4 \\
5 \\
6 \\
7\end{array}$ & $\begin{array}{l}-19 \\
+15 \\
-37 \\
-24 \\
+29 \\
-25 \\
-27\end{array}$ & $\begin{array}{r}69 \\
291 \\
139 \\
11 \\
28 \\
205 \\
212\end{array}$ & $\begin{array}{l}1 \times 10^{-5} \\
2 \times 10^{-5} \\
9 \times 10^{-6} \\
1 \times 10^{-5} \\
4 \times 10^{-4} \\
8 \times 10^{-5} \\
4 \times 10^{-4}\end{array}$ & $\begin{array}{l}1 \\
2 \\
3 \\
4 \\
5 \\
6\end{array}$ & $\begin{array}{l}-61 \\
-7 \\
-25 \\
-24 \\
+20 \\
-23\end{array}$ & $\begin{array}{l}63 \\
30 \\
40 \\
30 \\
76 \\
53\end{array}$ & $\begin{array}{l}7 \times 10^{-5} \\
2 \times 10^{-4} \\
2 \times 10^{-4} \\
2 \times 10^{-4} \\
1 \times 10^{-4} \\
2 \times 10^{-4}\end{array}$ \\
\hline \multicolumn{4}{|c|}{ Sample $85-1,87-89 \mathrm{~cm}$} & \multicolumn{4}{|c|}{ Sample $107-1,30-32 \mathrm{~cm}$} \\
\hline $\begin{array}{l}1 \\
2 \\
3 \\
4 \\
5 \\
6 \\
7 \\
7 \\
8 \\
9\end{array}$ & $\begin{array}{l}-8 \\
+35 \\
-26 \\
-19 \\
+10 \\
-59 \\
+25 \\
-2 \\
+20\end{array}$ & $\begin{array}{r}74 \\
225 \\
76 \\
291 \\
92 \\
338 \\
75 \\
246 \\
262 \\
\end{array}$ & $\begin{array}{l}2 \times 10^{-5} \\
1 \times 10^{-5} \\
2 \times 10^{-5} \\
2 \times 10^{-5} \\
1 \times 10^{-4} \\
2 \times 10^{-4} \\
3 \times 10^{-4} \\
3 \times 10^{-4} \\
7 \times 10^{-5}\end{array}$ & $\begin{array}{l}1 \\
2 \\
3 \\
4 \\
5 \\
6 \\
7\end{array}$ & $\begin{array}{l}-53 \\
-8 \\
-32 \\
+23 \\
-77 \\
+68 \\
-66\end{array}$ & $\begin{array}{r}0 \\
84 \\
103 \\
52 \\
257 \\
153 \\
345\end{array}$ & $\begin{array}{l}2 \times 10^{-3} \\
4 \times 10^{-3} \\
1 \times 10^{-3} \\
2 \times 10^{-2} \\
1 \times 10^{-2} \\
4 \times 10^{-3} \\
4 \times 10^{-3}\end{array}$ \\
\hline
\end{tabular}

Note: Remanence of breccia pieces from SDD: inclination $(I)$, declination $(D)$, and remanence intensity $(J)$ in $\mathrm{emu} / \mathrm{cm}^{3}$ of the pieces referred to in Figure 7. (Declination is with respect to an arbitrary sample reference frame.) 
by their removal is small. The NRM directions of three of the Hole 504B samples (80-3, 9-11 cm; 85-1, 87-89 $\mathrm{cm}$; and $107-1,30-32 \mathrm{~cm}$ ) appear to be essentially random. Sample 504B-91-1, 21-23 cm does, however, show some consistency. This is probably because many of the pieces appear to be close to their original orientation, at least with respect to each other.

Although there is no apparent pattern to the total remanence of these pieces, they may still have a part of their magnetization in common. This could result, for example, from heating by hydrothermal circulation producing a partial TRM, which would show up as a common low coercivity component in the Zijderveldt plots of each piece. Unfortunately, most of the sample is destroyed in the process of removing the pieces. What can be done is to compare the Zijderveldt plots of the whole sample to that of the last remaining piece. These are shown in Figure 7, where the declinations of the whole samples have been omitted for clarity.

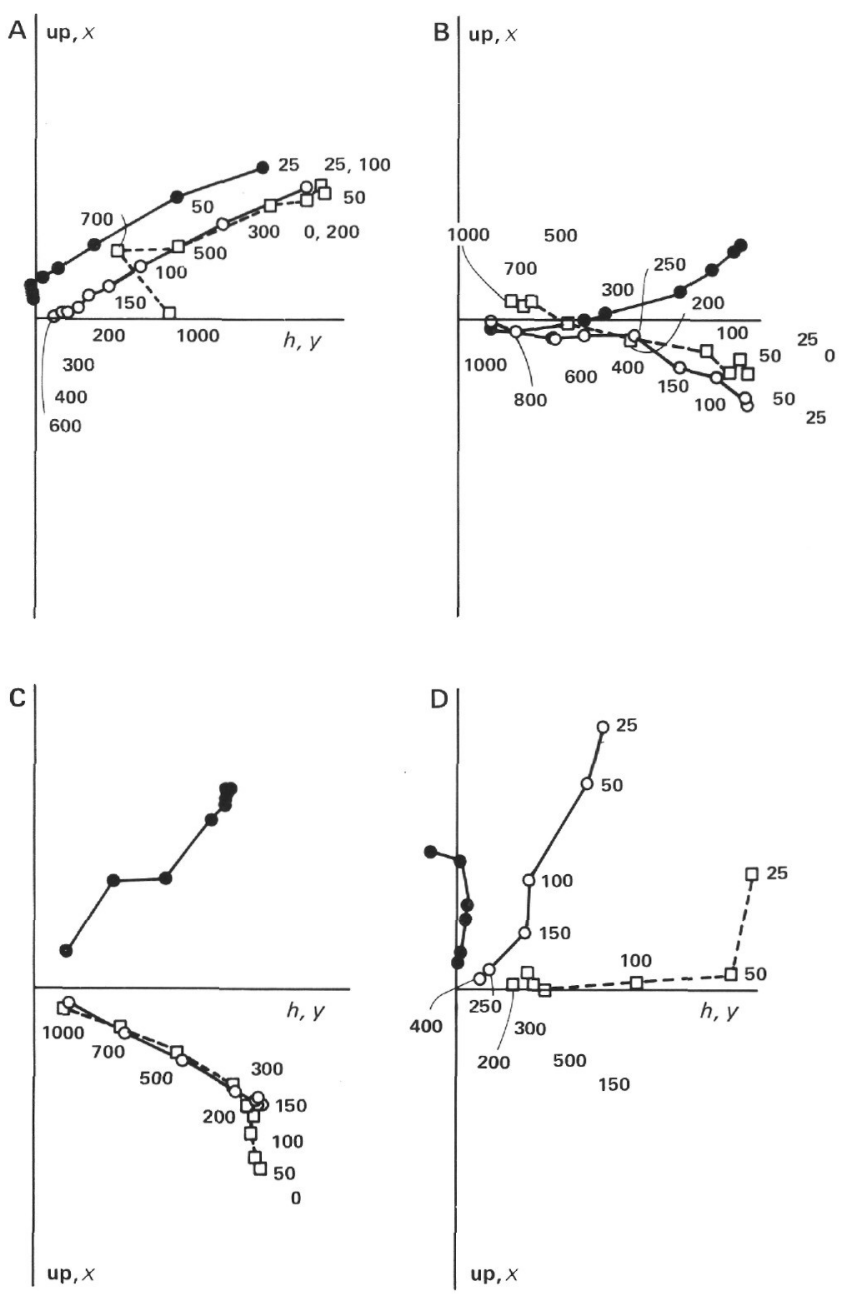

Figure 7. Zijderveldt plots for demagnetization of the last pieces of each SDD sample. (A) Sample 504B-80-3, 9-11 cm; (B) Sample 504B-85-1, 87-89 cm; (C) Sample 504B-91-1, 21-23 cm; and (D) Sample 504B-107-1, 30-32 cm. Closed circles represent the $x-y$ component open ones the vertical plane. Squares with dashed lines show the vertical plane component of the whole sample.
Samples 504B-80-3, 9-11 cm appears at first glance to have the postulated low coercivity overprint. However, the demagnetization levels do not compare at all, and the declination (not shown) has very different behavior for the two samples. Sample 504B-85-1, 87-89 $\mathrm{cm}$ may have an overprint, as the two inclination curves are similar at low fields. The declination curves (not shown) are not that similar, however, and the inclination behavior may be fortuitous. Sample 504B-91-1, 21-23 $\mathrm{cm}$ shows the reverse of the postulated behavior, a common high coercivity component. The low coercivity component must be carried by another portion of the sample as Piece 6 is completely stable to 200 Oe. Sample 504B-107-1, 30-32 cm shows similarities only for the portion below $50 \mathrm{Oe}$. Since remanences in this range could be viscous or caused by drilling or handling, their relation to the formation of the breccia is questionable at best. While it is possible that the low coercivity portion of these samples represents random laboratory acquired remanences, it seems unlikely. The most probable explanation is that the remanence of the clasts was acquired prior to consolidation of the breccia and was substantially unaffected by subsequent events.

The magnitude of remanence of the various pieces is also of interest. Sample 504B-80-3, 9-11 cm varied from $1 \times 10^{-5}$ to $4 \times 10^{-4} \mathrm{emu} / \mathrm{cm}^{3}$, one to two orders of magnitude greater than the NRM of the bulk sample $\left(2 \times 10^{-6}\right)$. The random orientation is clearly responsible for the low remanence, not any intrinsic rock magnetic properties. It is interesting that the remanence of the matrix material (Pieces 3-6) was comparable to the clasts (Pieces 1, 2, 7). Their magnetization is also nonuniform with substantial variations in direction for different portions.

Sample 504B-85-1, 87-89 cm contains no large fragments and two regions are largely quartz, presumably of hydrothermal origin. Surprisingly, the quartz regions had the highest NRMs (two orders of magnitude greater than the bulk NRM), and they also had different orientations. Otherwise, the sample looked much like Sample 504B-80-3, 9-11 cm with randomly oriented, relatively high remanence regions.

Sample 504B-91-1, 21-23 cm is the only one that shows any consistency between pieces with similar magnitudes as well as the similar directions discussed previously.

Sample 504B-107-1, 30-32 cm is similar to Sample 504B-80-3, 9-11 cm with a wide variation of magnitudes and high values for fine-grained brecciated areas as well as the clasts. NRM magnitudes were generally greater than the bulk values.

One interesting observation is that all of the fragments that were fully stepwise demagnetized appear to have been magnetized in two or more episodes with a different field and/or orientation present at each.

\section{Thermal Demagnetization and TRM}

Since the magnetization of these samples is controlled by a low Ti titanomagnetite and is relatively stable thermally, we decided to attempt some thermal demagnetization and TRM induction. ARM measurements before and after thermal demagnetization showed significant 
alteration in all samples studied. It is uncertain at what temperature the alteration started or what effect there was on remanence. The results are, accordingly, of dubious value and are not reported here.

The second experiment was to induce a laboratory TRM in several samples. ARM intensity and stability were determined before $\left(\mathrm{ARM}_{1}\right)$ and after heating $\left(\mathrm{ARM}_{2}\right)$ to check for alteration. Only Sample 504B-792, 14-16 cm had similar ARM intensities and demagnetization curves before and after heating. It is interesting that some samples showed minimal changes in ARM intensity but substantial changes in stability. Clearly, both measurements are necessary for a proper characterization. Figure 8 shows the four demagnetization curves $\left(\mathrm{ARM}_{1}, \mathrm{ARM}_{2}, \mathrm{NRM}\right.$, and TRM). The ratio of $\mathrm{ARM}_{2}$ to $\mathrm{ARM}_{1}$ was 1.2 , the ratio of TRM to NRM was 6.6 , and the ratio of $\mathrm{ARM}_{2}$ to TRM was 0.24.

\section{DISCUSSION}

The general impression is one of complexity, particularly in the transition zone and, to a lesser extent, in the dike complex. It is fairly safe to say that there is a minimum in magnetization in the transition zone, largely due to a reduction in the amount of magnetic minerals present. Beyond this the situation is less clear.

The behavior of the inclination with depth is similar to that observed in the upper $500 \mathrm{~m}$ (Furuta and Levi, 1983). It is conceivable that some of this could be caused by secular variation, as a perusal of an inclination map (e.g., Garland, 1982) shows that variations of $\pm 25^{\circ}$ are plausible. This does not, however, explain the large negative inclinations seen for some samples, or the large variations over short distances seen in some places. The most likely explanation is that some tectonic disruption, either local (e.g., small-scale faulting) or regional, is responsible for at least some of the anomalous inclinations. A third possibility is that a geomagnetic excursion

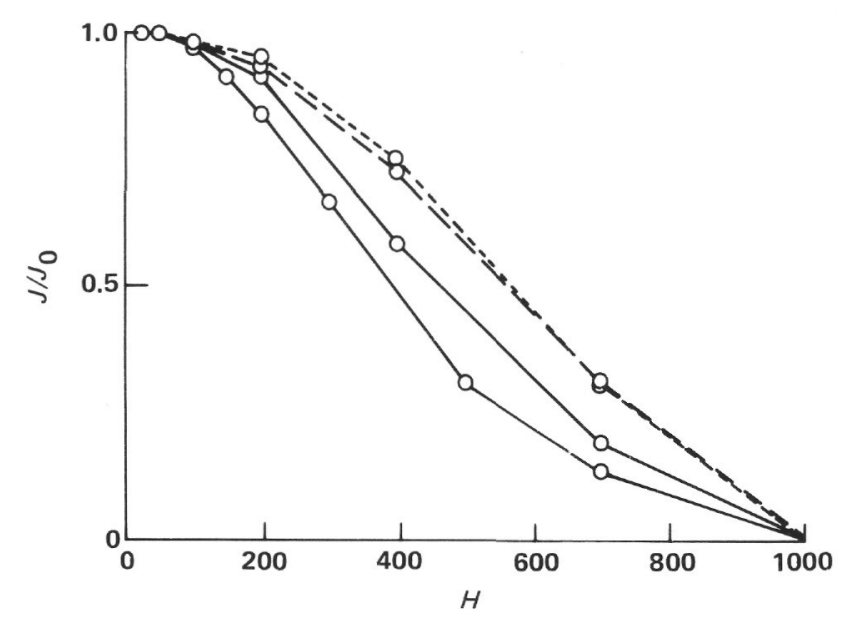

Figure 8. Comparison of AF demagnetization curves of Sample 504B$79-2,14-16 \mathrm{~cm}$. Lower solid line represents the NRM, the upper, the laboratory-induced TRM. The two dashed lines represent the ARMs given before (long dashes) and after (short dashes) TRM induction. The vertical axis gives the ratio of measured to total remanence and the horizontal gives the peak demagnetization field (in Oe). fortuitously occurred during the time these rocks were being magnetized, although this seems somewhat unlikely.

The behavior shown by the Zijderveldt diagrams indicates that the complexity is present on a local scale as well since many of the samples show evidence of two or more components. This suggests multiple episodes of magnetization coupled with tectonic disturbance or a sufficient time lapse for the field to change significantly (or perhaps both).

The origin of remanence is not completely clear, but it seems most likely that it is partly or wholly chemical in origin. The major piece of evidence for this assertion is the magnetic mineralogy. The upper $500 \mathrm{~m}$ contains, for the most part, typical low-temperature altered titanomagnetites (Furuta, 1983). As such, it is reasonable to suppose that the same was originally true of at least the extrusive portion recovered by Leg 83 . The uniformly high Curie points observed for these rocks indicate that substantial alteration has subsequently taken place, probably either by inversion of the original low-temperature oxidized titanomagnetites or by direct oxidation to a mixed-phase state. In the most highly altered rocks partial replacement of titanomagnetite by sphene may also be a factor. This alteration will produce a remanence with vastly different characteristics from the original TRM and should be properly considered a CRM. (The fraction of grains with blocking temperatures below those of the hydrothermal system $\left[<400^{\circ} \mathrm{C}\right]$ would actually carry a TRM or, more precisely, a PTRM.) The relation of the direction of CRM to the original TRM is less clear. What work is available on this sort of CRM (Bailey and Hale, 1981) suggests that the direction will change unless the ambient field is unusually low $(\approx 0.1$ Oe). Lacking evidence on the contrary, we will assume that the CRM of these samples involves a resetting of the direction of remanence.

The situation with the dike rocks is less clear. It seems likely that the composition of the original titanomagnetites is similar to that of the extrusives as the whole rock compositions are essentially identical. Ophiolite work has suggested that the magnetization of the dikes could be carried by titanomagnetites deuterically altered above $T_{c}$ and carrying a TRM (e.g., Swift and Johnson, in press; Luyendyk et al., 1982). Preliminary polished-section examination, however, shows no evidence of the lamellar structures to be expected if deuteric alteration had occurred (e.g., Haggerty, 1976). We tentatively conclude that the magnetic carriers are titanomagnetites that have undergone phase separation, probably in a similar fashion to the extrusive units, and carry a similar CRM.

In addition to alteration of existing magnetic phases, secondary magnetic minerals also may exist. One suggestion of this is the high remanence carried by the matrix material of the breccias. If the remanence were simply the sum of all the lithic fragments (which are presumably comparable to the larger clasts), then the net remanence should be much less than an intact piece of rock. In fact, they are comparable. Either the magnetization of these fragments has been reset (unlike the larger clasts), or their magnetization is much larger than the 
clasts measured (which seem unlikely), or there are secondary magnetic minerals carrying the remanence. The quartz region of Samples 504B-85-1, 87-89 cm appear to be completely hydrothermal in origin and carry a high remanence. Finally, a secondary opaque phase that appears to be magnetite has been observed in Sample 504B-107-1, 30-32 cm. It seems quite possible that secondary minerals may contribute significantly to the magnetization of the breccias. Whether this is also true of the intact basalts is a question for future study.

Since these samples appear to be carrying primarily a CRM, an obvious question is whether or not it has any distinctive magnetic characteristics. A number of workers (e.g., Levi and Merrill, 1976) have shown that, for pure magnetite, ARM and TRM have similar AF demagnetization curves with ARM magnitudes somewhat less than half those of TRM. In contrast, the Leg 83 sample have consistently more stable ARMs with relative magnitudes ranging from 0.8 to 22.0. The TRM induction experiment discussed previously was intended to test whether this behavior was diagnostic of a CRM. The results are rather tentative, being based on only one sample. In fact, the NRM is less stable than TRM, but both fall below ARM. While it appears that CRM may be significantly less stable than TRM, the ARM-TRM analogy does not appear to be valid, rendering comparison of ARM and NRM demagnetization spectra invalid as a diagnostic tool. The TRM magnitude, on the other hand, is about what was seen for pure magnetite, suggesting that a large value of $J_{A} / J_{N}$ may be characteristic of CRM. It is perhaps worth noting that a large TRM/ CRM ratio is consistent with the work of Kobayashi (1962), although he studied a rather different type of CRM (CRM resulting from growth of magnetic grains).

The breccias offer some interesting insights into the nature of the fluid circulation. The largely random orientation of magnetization of the clasts in three of the Hole 504B samples $(80-3,9-11 \mathrm{~cm}$; 85-1, 87-89 cm; 107$1,30-32 \mathrm{~cm}$ ) indicates that the magnetization must have been largely acquired prior to emplacement in the breccia, suggesting that subsequent temperatures must have been low (Samples 504B-80-3, 9-11 cm was thermally demagnetized and showed changes in remanence at temperatures as low a $100^{\circ} \mathrm{C}$, although this may have been due to alteration). Demagnetization of individual clasts indicates that they have undergone at least two episodes of magnetization, suggesting a complex history prior to emplacement.

The relation of these results to the question of the origin of magnetic lineations and the applicability of the ophiolite model is equivocal. The transition units clearly cannot contribute significantly to the anomaly, regardless of inclination variations. The remanence is much too low. Although relatively high intensities were observed for some dike samples, it is unclear how common they are and to what depth they extend. The intensity data are also complicated by the variability in inclination, which tends to reduce the net signal.

The relationship of ophiolite magnetic properties to ocean crust (especially the dike complex) remains another question. Luyendyk et al. (1982) found a large scat- ter in inclination in the dikes of the Samail ophiolite. This similarity to Hole 504B may be fortuitous as the large scatter in the upper $500 \mathrm{~m}$ (Furuta and Levi, 1983) suggests that it may arise from factors not intrinsic to the dikes themselves. NRM values and rock magnetic parameters are similar to those at Samail (Luyendyk et al., 1982), Troodos, and Smartville (Banerjee, 1980) in contrast to the much lower NRMs seen for the Bay of Islands (Swift and Johnson, in press) and Macquarie Island (Banerjee, 1980). The magnetic mineralogy of the dikes appears to be different from either the Samail or Bay of Islands rocks. The thin sections examined show neither the deuteric alteration structures seen by Swift and Johnson (in press) nor the secondary hematite seen by Luyendyk et al. (1982). This conclusion is based on a brief examination of a small number of slides, however, and should be regarded as very tentative. In any event, only a small portion of the dike complex was sampled by Hole 504B cores and we may be comparing results from quite different depths.

\section{SUMMARY}

The available evidence suggests that the remanence of these rocks is partly or wholly chemical in origin. Although not certain, it seems most likely that the direction of the original TRM is reset when the CRM is acquired. The magnetization shows complexity both on a local scale, with many samples having two or more components of remanence, and on a larger scale, with highly variable inclinations over relatively short distances along the core. SDD of the breccias indicates that the clasts were magnetized, probably a CRM, prior to consolidation and the remanence was not subsequently modified by either thermal or chemical activity. There is evidence in some of the breccias that secondary mineralization included some magnetic phases, although it is unclear how widespread these are and whether they occur in other rock types.

Comparison of this section with ophiolite work shows some similarities as well some differences. Given the limited penetration of the dike complex, any conclusions on this issue would seem premature. The depth of the magnetized zone is also unresolved. The transition zone clearly contributes negligibly to the magnetic anomaly. The presence of some relatively high magnetization dike rocks, however, leaves the question open as to whether and to what depth the dike complex affects anomaly measurements at the surface.

A plausible scenario for the magnetization of these rocks is that it was largely acquired at some time after emplacement, probably as a result of heating and alteration related to hydrothermal circulation. This process was probably localized both spatially and temporally and, in many cases, involved two or more episodes of magnetization separated by tectonic disturbance and/or a sufficient time lapse for the ambient field to change significantly. Since these hydrothermal and tectonic processes have only a general correlation with stratigraphy, there seems no reason to expect that the acquisition of remanence should follow any simple pattern, hence the highly variable pattern of inclination. 


\section{ACKNOWLEDGMENTS}

We would like to thank Wendy Tormanen and Yvonne Meeks for their assistance with some of the measurements. Valuable assistance was also rendered by Jim Marvin. We would also like to thank our reviewers, particularly S. Beske-Diehl, for many helpful comments and criticisms. This work was performed under NSF Grants OCE-8018692 and OCE-8214652.

\section{REFERENCES}

Bailey, M. E., and Hale, C. J., 1981. Anomalous magnetic directions recorded by laboratory induced chemical remanent magnetization. Nature 294:739-741.

Banerjee, S. K., 1980. Magnetism of the ocean crust-evidence from ophiolite complexes. J. Geophys. Res., 85:3557-3566.

Beske-Diehl, S., and Banerjee, S. K., 1979. An example of magnetic properties as indicators of alteration in ancient oceanic lithosphere-the Othris ophiolite. Earth Planet Sci. Lett., 44:451-462.

Bleil, U., and Peterson, N., 1983. Variations in magnetization intensity and low temperature titanomagnetite oxidation of ocean floor basalts. Nature, 301:384-388.

Butler, R. F., Banerjee, S. K., and Stout, J. H., 1976. Magnetic properties of oceanic pillow basalts: Evidence from MacQuarie Island. Geophys. J. Roy. Astron. Soc., 47:179-196.

Chase, C. G., 1978. Extension behind island arcs and motions relative to hot spots. J. Geophys. Res., 83:5385-5387.

Day, R., Fuller, M. D., and Schmidt, U. A., 1977. Hysteresis properties of titanomagnetites: Grain size and composition dependence. Phys. Earth Planet. Intern., 13:260.

Furuta, T., 1983. Magnetic properties of basalt samples from Holes 504B and 505B on the Costa Rica Rift, Deep Sea Drilling Project Legs 69 and 70. In Cann, I. R., Langseth, M. G., Honnorez, J., Von Herzen, R. P., White, S. M., et al., Init. Repts. DSDP, 69: Washington (U.S. Govt. Printing Office), 711-720.
Furuta, T., and Levi, S., 1983. Basement paleomagnetism of Hole 504B. In Cann, I. R., Langseth, M. G., Honnorez, J., Von Herzen, R. P., White, S. M., et al. Init. Repts. DSDP, 69: Washington (U.S. Govt. Printing Office). 697-704.

Garland, G. D., 1982. Introduction to Geophysics: Saunders. (Philadelphia).

Haggerty, S. E., 1976. Opaque mineral oxides in terrestrial igneous rocks. In Rumble, D. (Ed.), Oxide Minerals, Mineralogic Soc. Am. Short Course Notes, 3:101-140.

Johnson, H. P., 1979. Magnetization of the oceanic crust. Rev. Geophys. Space Phys., 17:215-226.

Kobayashi, K., 1962. Magnetization blocking process by volume development of ferromagnetic fine particles. J. Phys. Soc. Japan, 17: 695.

Larson, E. E., 1981. Selective destructive demagnetization, another microanalytic technique in rock magnetism. Geology, 9:350-355.

Levi, S., Banerjee, S. K., Beske-Diehl, S., and Moskowitz, B., 1978. Limitations of ophiolite complexes as models for the magnetic layer of the oceanic lithosphere. Geophys. Res. Lett., 5:473-476.

Levi, S., and Merrill, R. T., 1976. A comparison of ARM and TRM in magnetite. Earth Planet. Sci. Lett., 32:171-184.

Luyendyk, B. P., Laws, B. R., Day, R., and Collinson, T. B., 1982. Paleomagnetism of the Samail ophiolite, 1, the sheeted dike complex at Ibra. J. Geophys. Res., 87:10,883-10,902.

Moskowitz, B. M., 1981. Methods for estimating Curie temperatures of titanomagnetites from experimental $\mathrm{J}_{\mathrm{s}}-\mathrm{T}$ data. Earth Planet. Sci. Lett., 53:84-88.

Stacey, F. D., and Banerjee, S. K., 1974. The Physical Principles of Rock Magnetism: New York (Elsevier).

Swift, B. A., and Johnson, H. P., in press. Magnetic properties of the Bay of Islands ophiolite suite and implications for the magnetization of the ocean crust. J. Geophys. Res.

Date of Initial Receipt: 19 April 1982

Date of Acceptance: 12 October 1983 